\title{
Telaah Matematis Perhitungan Arah Kiblat Rumus Cos-Sin Dengan Rumus Tan dalam Dasar- Dasar Ilmu Ukur Segitiga Bola
}

\author{
Agus Solikin ${ }^{1}$ \\ UIN Sunan Ampel Surabaya \\ 1Email: agussolikin2@gmail.com
}

\begin{abstract}
The research aims to tackle the problem of mathematical analysis in the cos-sin formula and the tan formula for calculating the Qibla direction in spherical measurement with its relation to the estimating formula for the qibla direction in the celestial literature. The research is design into a qualitative descriptive study. Based on the research conducted, there are two results, first, mathematically, the cos-sin formula and the formula for calculating the Qibla direction in spherical measurement have a relation to the calculation of the qibla direction, it is the rules for cos and sin of spherical triangles. Secondly, there are other forms of qibla direction formulas rarely found in the astronomical literature.
\end{abstract}

Keywords : Calculation, Qibla Direction.

\begin{abstract}
Abstrak
Masalah dalam penelitian ini yaitu telaah matematis terhadap rumus $\cos -\sin$ dan rumus tan perhitungan arah kiblat dalam ilmu ukur bola, serta relasinya dengan rumus perhitungan arah kiblat dalam literatur falak. Untuk menjawab masalah tersebut, maka penelitian ini dirancang ke dalam penelitian deskriptif kualitatif, Berdasarkan penelitian yang dilakukan dapat diambil kesimpulan dua hal bahwa, pertama secara matematis rumus $\cos$ - sin dan rumus tan perhitungan arah kiblat dalam ilmu ukur bola memiliki relasi dengan rumus perhitungan arah kiblat dalam literatur falak yaitu aturan cos dan sin segitiga bola. Kedua, ada bentuk rumus arah kiblat lain namun jarang diketemukan dalam literatur falak.
\end{abstract}

Kata Kunci : Perhitungan, Arah Kiblat.

\section{Artikel Info}

Received:

01 Agustus 2020

Revised:

19 September 2020

Accepted:

09 November 2020

Published:

02 Desember 2020 


\section{AL-MARSHAD: JURNAL ASTRONOMI ISLAM DAN ILMU-ILMU BERKAITAN \\ ISSN 2442-5729 (print) || ISSN 2598-2559 (online) \\ http://jurnal.umsu.ac.id/index.php/almarshad \\ DOI: 10.30596/jam.v\%vi\%i.5023|| Vol. 6, No. 2 Desember 2020}

\section{A. Pendahuluan}

Proses penentuan arah kiblat pada hakikatnya adalah proses melakukan perhitungan arah antara dua tempat dari suatu tempat yang ditentukan arah kiblatnya tertentu menuju ke Ka bah. Arah yang dimaksud dalam kajian matematik disebut dengan jarak sferis. Jarak sferis antara dua tempat A dan B adalah jarak terpendek pada permukaan bola di tempat tersebut ${ }^{1}$, artinya jarak yang digunakan adalah jarak terdekat antara dua tempat tersebut.

Selaras dengan hal itu, penentuan arah kiblat merupakan bagian dari khazanah keilmuan agama yang dipelajari dalam ilmu falak, Ilmu falak (ilmu hisab) memiliki perhitungan astronomis berkaitan dengan posisi Bulan dan Matahari, yang semuanya diorientasikan relasinya dengan ibadah. ${ }^{2}$, namun yang perlu diketahui, arah kiblat tidak selamanya berhubungan dengan salat saja, melainkan juga dalam kehidupan dan budaya umat Islam yang lainnya, diantaranya yaitu menguburkan jenazah umat Islam. ${ }^{3}$

${ }^{1}$ Kusdiono Ilmu Ukur Segitiga Bola,. (Bandung: Jurusan teknik geodesi Institut Teknologi Bandung,2002), h. 5.

${ }^{2}$ Slamet Hambali,Ilmu Falak. (Semarang: Program pascasarjana IAIN Walisongo.2011).h.5

${ }^{3}$ Hosen dan Eka Nurhalisa. Akurasi Arah Kiblat Pemakaman Desa Ponteh Kecamatan Galis Kabupaten Pamekasan. (Medan: AlMarshad.Vol.5 no.2 tahun 2019). h. 148.
Selanjutnya, berdasarkan data yang ada, Bumi yang menjadi salah satu obyek kajian falak diantaranya terkait dengan masalah kiblat didiskripsikan berbentuk bola. Pemodelan atau pendeskripsian bentuk Bumi dipelajari dalam ilmu astronomi dan perkembangan ilmu astronomi telah membuktikan bahwa sebenarnya Bumi tidak seperti bola atau bulat penuh, melainkan pipih di kedua kutubnya, dengan diameter kutub 12.713,56 KM, sedangkan diameter equatornya $12.756,28 \mathrm{KM}^{4}$

Pendeskripsian Bumi bentuknya seperti bola dengan jari-jari 6370 KM akan memudahkan dalam proses perhitungan, dan hasilnya juga sudah cukup akurat. Begitu pula dalam perhitungan arah kiblat, buku-buku falak maupun ilmu ukur bola juga mendiskripsikan bentuk Bumi seperti bola, salah satu buku yang mendiskripsikan Bumi berbentuk bola yaitu buku dasar - dasar ilmu ukur segitiga bola yang ditulis oleh Slamet Hw.

Selaras dengan itu, di dalam bukunya yang telah diterbitkan oleh Muhammadiyah Univesrsity Press Slamet Hw menyebutkan bahwa perhitungan arah kiblat ada lima rumus

Lihat pula Veli İLÇ̇, Dkk. Investigation On The Accuracy Of Existing Qibla Directions Of The Mosques From Different Periods: A Case Study In Corum City, Turkey. (Slavonski Brod, Croatia: Technical Gazette, Vol. 25 No. 6, 2018). P. 1642

4 Agus Purwanto. Penentuan arah Kiblat. makalah Pelatihan Hisab Falak, di PWM Jatim, tanggal 10 Juli 2011 


\section{AL-MARSHAD: JURNAL ASTRONOMI ISLAM DAN ILMU-ILMU BERKAITAN \\ ISSN 2442-5729 (print) || ISSN 2598-2559 (online) \\ http://jurnal.umsu.ac.id/index.php/almarshad \\ DOI: 10.30596/jam.v\%vi\%i.5023|| Vol. 6, No. 2 Desember 2020}

yaitu rumus cos-sin, rumus analogi Napier, rumus tan dan sudut bantu $\mathrm{P}$, serta rumus haversine ${ }^{5}$. Selaras dengan itu, pada sisi yang lain, rumus perhitungan arah kiblat dalam literatur-literatur falak sering disebut dengan rumus arah kiblat.

Berikutnya, menarik untuk dicermati terkait dengan lima rumus tersebut di atas, yaitu belum dijelaskannya kaidah atau asal usul secara matematik dan astronomi tentang proses rumusrumus tersebut diperoleh. Secara umum rumus-rumus tersebut tidak ada masalah, namun menurut penulis perlu adanya penjelasan mengenai proses diperolehnya rumus-rumus tersebut. Sehingga pada akhirnya akan didapatkan pengetahuan/keilmuan yang utuh antara matematika, astronomi, dan falak atau dengan bahasa lain akan terlihat kerkaitan, ketersapaan, atau interkoneksi antara beberapa ilmu dalam perhitungan arah kiblat.

Seirama dengan itu, sebagaimana dijelaskan oleh Butar Butar bahwa pada umumnya, manuskrip manuskrip sains senantiasa memuat jadwal, skema dan rumus. Dalam penulisan jadwal, skema, dan rumus tersebut ada tiga kemungkinan penulisan yang dilakukan oleh penulisnya

\footnotetext{
${ }^{5}$ Slamet Hw. Dasar-dasar Ilmu Ukur Segitiga Bola.(Surakarta:Muhammadiyah University Press. 2018). h. 36-37
}

yaitu : (1) adakalanya penulis naskah menukil secara sempurna dan menjaga keautentikan jadwal dengan penyempurnan yang sesuai, (2) adakalanya penulis naskah mengabaikan (menghilangkan) jadwal-jadwal tersebut, (3) adakalanya penulis naskah menukil sebagaimana ia dapati dari naskah yang ia temukan tanpa penambahan atau pengurangan ${ }^{6}$. Berdasarkan penjelasan ButarButar tersebut, maka rumus perhitungan arah kiblat tersebut membuka peluang unuk dikaji secara matematis, sehingga dieroleh gambaran rumus tersebut secara utuh tentang penukilan rumus tersebut masuk dalam kategori dinukil yang sempurna, dihilangkan sebagian, atau dinukil tanpa penambahan dan pengurangn.

Selaras dengan uraian tersebut di atas, maka dalam karya tulis ini penulis bermaksud untuk mengangkat tentang telaah matematika dan astronomi terhadap rumus perhitungan arah kiblat yang ada dalam Buku Dasar Dasar Ilmu Ukur Segitiga Bola karya Slamet $\mathrm{Hw}$, dengan fokus kajian pada rumus cos-sin dan tan. Selain itu, penulis juga akan merelasikan dua rumus tersebut dengan rumus arah kiblat yang ada dalam literatur- literatur falak.

6 Arwin Juli Rakhmadi Butar-Butar. Khazanah Peradaban Islam Di Bidang Turats Manuskrip (Telaah Karakteristik, Konstruksi Dan Problempenelitian Naskah-Naskah Astronomi). (Medan: AlMarshad.Vol.1 no.1 2015). h. 72 


\section{AL-MARSHAD: JURNAL ASTRONOMI ISLAM DAN ILMU-ILMU BERKAITAN \\ ISSN 2442-5729 (print) || ISSN 2598-2559 (online) \\ http://jurnal.umsu.ac.id/index.php/almarshad \\ DOI: 10.30596/jam.v\%vi\%i.5023|| Vol. 6, No. 2 Desember 2020}

Akhir dari kajian ini, penulis memperoleh sebuah gambaran tentang penjelasan dan pengertian rumus-rumus yang menjadi fokus pada kajian ini.

\section{B. Metode Penelitian}

\section{Jenis dan Sumber data Penelitian}

\section{a. Jenis Penelitian}

Menurut Suryana ${ }^{7}$ penelitian dapat dibedakan menjadi dua jenis yaitu berdasarkan sifat masalahnya dan berdasarkan tujuannya. Berdasarkan sifat masalahnya penelitian ini dirancang sebagai penelitian deskriptif yang bertujuan untuk membuat deskripsi secara sistematis,faktual dan akurat mengenai fakta-fakta yang ada, terkait dengan rumus-rumus perhitungan arah kiblat rumus cos-sin dan rumus $\tan ^{8}$. Sedangkan berdasarkan tujuannya, maka penelitian ini juga termasuk penelitian deskriptif, karena penelitian ini bertujuan untuk mengetahui proses matematis diperolehnya rumusrumus perhitungan arah kiblat yang ada dalam buku tersebut, yang meliputi rumus cos-sin dan tan .

Ditetapkannya tujuan tersebut, Berdasarkan hal tersebut, maka penelitian ini dirancang termasuk ke dalam jenis penelitian diskriptif kualitatif.

\footnotetext{
7 Suryana, Metodologi Penelitian. (Bogor: Universitas Pendidikan Indonesia.2010). h. 18 ${ }^{8}$ Op.cit.
}

\section{b. Sumber Data Penelitian}

Moleong $^{9}$ menyebutkan sumber data utama dalam penelitian kualitatif adalah kata-kata dan tindakan. Berkaitan dengan hal itu, maka kata-kata yang dimaksud dalam penelitian ini, yaitu kata-kata yang diperoleh dari sumbersumber tertulis.

Secara terperinci, sumber data dalam penelitian ini ada dua yaitu sumber data primer, dan sumber data skunder. Sumber data primer dalam penelitian ini yaitu buku Buku Dasar Dasar Ilmu Ukur Segitiga Bola karya Slamet $H w$.

Sumber data skunder dalam penelitian ini adalah karya-karya lain yang langsung berkaitan atau tidak berkaitan.

\section{Metode Pengumpulan Data}

Metode pengumpulan data pada penelitian ini yaitu dengan dokumentasi penelaahan dokumen-dokumen yang terkait dengan obyek penelitian, penelaahan dokumen dilakukan dengan secermat mungkin dan diupayakan diambil dari sumber dokumen aslinya.

\section{Metode Analisis Data}

Data yang diperoleh diklasifikasikan ke dalam data utama

\footnotetext{
9 Moleong, Lexy J, Metodologi Penelitian Kualitatif, (Bandung: PT Remaja Rosdakarya.2005).h. 157
} 


\section{AL-MARSHAD: JURNAL ASTRONOMI ISLAM DAN ILMU-ILMU BERKAITAN \\ ISSN 2442-5729 (print) || ISSN 2598-2559 (online) \\ http://jurnal.umsu.ac.id/index.php/almarshad \\ DOI: $10.30596 /$ jam.v\% vi\%i.5023|| Vol. 6, No. 2 Desember 2020}

dan data pendukung. Kemudian data dianalisis dengan menggunakan metode deskriptif analitis induktif. Analisis induktif dilakukan karena, menurut Moleong ${ }^{10}$ dapat menemukan kenyataan secara keseluruhan seperti yang terdapat dalam data. Proses akhir analisis data yaitu dengan penarikan kesimpulan.

\section{Hasil Dan Pembahasan}

\section{Hasil Penelitian}

\section{a. Rumus Arah Kiblat Dalam}

\section{Ilmu Ukur Bola}

Guna memahami konsep matematis dalam penentuan arah kiblat maka perlu dipahami terlebih dahulu posisi tempat yang akan dilakukan pengukuran kiblatnya, yang dalam hal ini yaitu Yogyakarta dengan posisi ka'bah. Posisi dua tempat tersebut dapat digambarkan sebagai berikut ${ }^{11}$ :

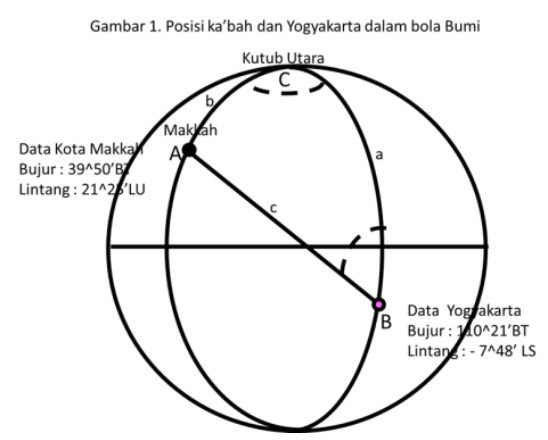

${ }^{10}$ Ibid. h. 10

${ }^{11}$ Slamet Hw. Dasar-dasar Ilmu Ukur Segitiga Bola.(Surakarta:Muhammadiyah University Press. 2018). h. 35
Sebagaimana dijelaskan dalam aturan segitiga bola, maka gambar di atas bisa disederhanakan guna memudahkan analisis matematisnya sebagai berikut ${ }^{12}$ :

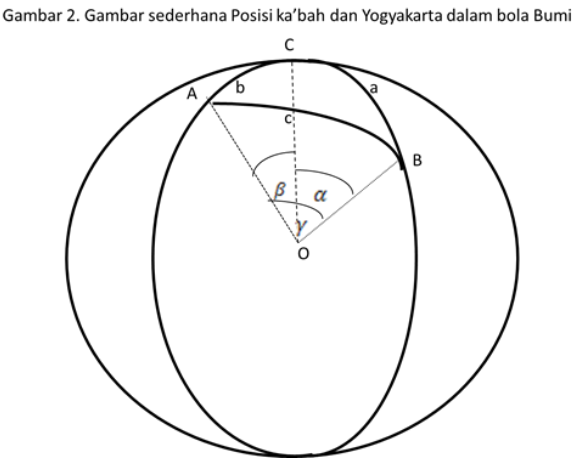

Dari gambar 2 tersebut pula akhirnya diperoleh segitiga bola $\mathrm{ABC}$ dengan panjang sisi a, b, dan c serta sudutsudutnya yaitu $\mathrm{CAB}, \mathrm{ABC}$, dan BCA. Berdasarkan gambar tersebut pula diketahui bahwa ${ }^{13}$ :

1) Dalam gambar tersebut ada dua tempat yaitu A dan B. A berada dalam lintang $(\phi)$ dan bujur $(\lambda)$ tertentu, yang selanjutnya ditulis dengan $\phi_{A}$ dan $\lambda_{A}$. Begitu pula dengan $B$ juga berada dalam lintang $(\phi)$ dan bujur $(\lambda)$ tertentu, yang selanjutnya ditulis dengan $\phi_{B}$ dan $\lambda_{B}$

2) Berdasarkan gambar tersebut di atas pula, dapat diambil sebuah segitiga bola $\mathrm{ABC}$, dengan sisi- 
sisinya yaitu a, b, dan c. Panjang masing-masing sisi secara matematis dapat ditentukan dengan rumus:

$$
\begin{aligned}
\mathrm{a}= & 90^{\circ}-\text { lintang tempat } \\
& \text { yang akan diukur } \\
& =90^{\circ}-\phi_{B} \\
b= & 90^{\circ}-\text { lintang tempat } \\
& \text { Ka'bah }=90^{\circ}-\phi_{A} \\
\mathrm{c}= & \text { Selisih bujur tempat } \\
& \text { yang akan diukur } \\
& \text { dengan bujur ka'bah } \\
& \left(\lambda_{A}-\lambda_{B}\right)
\end{aligned}
$$

Setelah nilai $a, b$, dan $C$ dapat ditentukan, maka nilai sudut CBA atau arah kiblat dari utara ke barat dapat ditentukan dengan rumus ${ }^{14}$

1) Rumus cos - sin, artinya bila diketahui a, b, dan C, maka

a) Langkah pertama yaitu menghitung panjang sisi $\mathrm{c}$ dengan rumus cos

$$
\begin{aligned}
& \cos C \\
& =\cos a \cos b \\
& +\sin a \sin b \cos C
\end{aligned}
$$

b) Kemudian dengan rumus sin, dapat dihitung B (arah kiblat)

$$
\sin B=\left[\frac{\sin b \sin c}{\sin C}\right]
$$

2) Rumus tan $\tan B$

$$
=\frac{\sin C}{(\sin a: \tan b-\cos a \cos C)}
$$

b. Rumus Arah Kiblat Dalam Literatur Falak

Rumus arah kiblat dalam literatur falak diantaranya ${ }^{15}$ dituliskan

$$
\begin{aligned}
\operatorname{cotan} B=\frac{\sin a \operatorname{cotan} b}{\sin C} \\
-\cos a \operatorname{cotan} C
\end{aligned}
$$

\section{Pembahasan}

a. Analisis matematik Rumus $\cos -\sin$ Guna menganalisis rumus $\cos -\sin$ ini, berdasarka gambar 2. dan menggunakan aturan cosinus dalam segitiga bola maka akan diperoleh sebuah persamaan:

$$
\begin{aligned}
& \cos b \\
& =\cos a \cos c \\
& +\sin a \sin c \cos B \\
& \cos c \\
& =\cos a \cos b \\
& +\sin a \sin b \cos C
\end{aligned}
$$

persamaan (2) ini yang sebenarnya rumus yang ada pada langkah nomor 1, yaitu menghitung panjang sisi c dengan

\footnotetext{
${ }^{15}$ Rumus perhitungan yang penulis tuliskan bisadi lihat dalam Susiknan Azhari. Ilmu falak peejumpn khazanah Islam dan sains modern (Yogyakarta: Suara Muhammadiyah. 2011). h.57. lihat pula Akh. Mukarram. Ilmu Falak Dasar - Dasar Hisab Praktis. (Sidoarjo: Grafika Media. 2011). h. 101. Lihat pula Abd. Salam Nawawi. Ilmu Falak (Sidoarjo: Aqaba. 2010). h. 37
} 
rumus $\cos ^{16}$.

Langkah berikutnya yang akan

dilakukan yaitu persamaan (2)

disubtitusikan ke persamaan (1)

$$
\begin{aligned}
& \cos b=\cos a \cos c \\
& +\sin a \sin c \cos B \\
& =\cos a(\cos a \cos b \\
& +\sin a \sin b \cos C) \\
& +\sin a \sin c \cos B \\
& =\cos ^{2} a \cos b \\
& +\cos a \sin a \sin b \cos C \\
& +\sin a \sin c \cos B
\end{aligned}
$$

Karena, dalam rumus identitas trigonometri diketahui bahwa $\cos ^{2} a=1-\sin ^{2} a, \quad$ sehingga diperoleh

$\cos b$

$=\cos ^{2} a \cos b$

$+\cos a \sin a \sin b \cos C$

$+\sin a \sin c \cos B$

$$
\begin{aligned}
& =\left(1-\sin ^{2} a\right) \cos b \\
& +\cos a \sin a \sin b \cos C \\
& +\sin a \sin c \cos B
\end{aligned}
$$

$$
=\cos b-\sin ^{2} a \cos b
$$$$
+\cos a \sin a \sin b \cos C
$$

$+\sin a \sin c \cos B$

Selanjutnya, $\sin ^{2} a \cos b$ yang berada berada di ruas kanan dipindah ke ruas kiri, sehingga diperoleh

$\cos +\sin ^{2} a \cos b$

$=\cos \mathrm{b}+\cos a \sin a \sin b \cos C$

$+\sin a \sin c \cos B$

Selanjutnya, $\cos b$ yang berada berada di ruas kiri dipindah ke ruas kanan, sehingga diperoleh

Langkah pertama menghitung panjang c, dikarenakan dalam segitiga bola pada gambar 2
panjang a dan b sudah diketahui, sedangkan panjang c belum diketahui. selain itu, dipilihanya lagkah ertama menggunakan atuaran cosinus dalamsegitiga bola dalam menentukan panjang sisis c, bukan aturan sinus dalam segita bola dikarenakan berdasarkan data yang sudah dikataui dalam segitiga bola $\mathrm{ABC}$, data yang sudah dekatui yaitu panjang a, panjang $b$, dan sudut $C$, sehingga rumus yang sangat memungkinkan yaitu pakai aturan cosinus,.

$$
\begin{aligned}
& \sin ^{2} a \cos b \\
& =\cos b \\
& -\cos b \\
& +\cos a \sin a \sin b \operatorname{Cos} C \\
& +\sin a \sin c \cos B \\
& =\cos a \sin a \sin b \operatorname{Cos} C \\
& \quad+\sin a \sin c \cos B
\end{aligned}
$$

Selanjutnya kedua ruas dibagi dengan sin a $\sin b$, dan diperoleh

$$
\begin{aligned}
& \frac{\sin ^{2} a \cos b}{\sin a \sin b} \\
& =\frac{\cos a \sin a \sin b \cos C+\sin a \sin c \cos B}{\sin a \sin b}
\end{aligned}
$$




$$
\begin{aligned}
\sin a \frac{\cos b}{\sin b}= & \cos a \cos C \\
& +\frac{\sin c}{\sin b} \cos B
\end{aligned}
$$

Sedangkan menurut aturan sinus ${ }^{17}$

$$
\begin{aligned}
& \text { segitiga bola } \frac{\sin c}{\sin b}=\frac{\sin C}{\sin B}, \text { maka } \\
& \qquad \begin{aligned}
\sin a \frac{\cos b}{\sin b}= & \cos a \cos C \\
& +\frac{\sin c}{\sin b} \cos B
\end{aligned}
\end{aligned}
$$

$\sin a \operatorname{cotan} b=\cos a \cos C$

$$
+\frac{\sin C}{\sin B} \cos B
$$

$$
\begin{aligned}
\sin \mathrm{a} \operatorname{cotan} \mathrm{b}= & \cos a \cos C \\
& +\frac{\cos B}{\sin B} \sin C
\end{aligned}
$$

$\sin a \operatorname{cotan} b=\cos a \cos C$

$$
+\sin C \operatorname{cotan} B
$$

Selanjutnya kedua ruas

dipindah atau ditukar

$$
\begin{aligned}
\cos a \cos C+ & \sin C \operatorname{cotan} B \\
& =\sin a \operatorname{cotan} b
\end{aligned}
$$

Selanjutnya, $\quad \cos a \cos C \quad \mathrm{di}$ ruas kiri dipindah ke ruas kanan

$$
\sin C \operatorname{cotan} B=\sin a \operatorname{cotan} b
$$

$$
-\cos a \cos C
$$

Berikutnya, $\sin C$ di ruas kiri dipindah ke kanan

\footnotetext{
${ }^{17}$ Aturan sinus digunakan pada tahap ini, sejatinya tidak lain yaitu langkah no 2 yaitu menggunakan aturan sinus dalam segitiga bola untuk menetukan arah kiblat.
}

$\operatorname{cotan} B$

$$
\begin{array}{r}
=\frac{\sin a \operatorname{cotan} b-\cos a \cos C}{\sin C} \\
\operatorname{cotan} B=\frac{\sin a \operatorname{cotan} b}{\sin C} \\
-\frac{\cos a \cos C}{\sin C}
\end{array}
$$

$$
\begin{aligned}
\operatorname{cotan} B=\frac{\sin a \operatorname{cotan} b}{\sin C} \\
-\cos a \frac{\cos C}{\sin C}
\end{aligned}
$$

$\operatorname{cotan} B$

$$
=\frac{\sin a \operatorname{cotan} b}{\sin C}
$$

$-\cos a \operatorname{cotan} C$

Persamaan (3) inilah yang kemudian dikenal dengan rumus arah kiblat rumus cosinus dan rumus sinus. Rumus ini pula yang kemudian sering digunakan dalam literatur - literatur falak $^{18}$.

Selaras dengan itu, maka dapat disimpulkan bahwa dua langkah yaitu menggunakan rumus cos dalam segitiga bola dan dilanjutkan dengan menggunkan rumus sin untuk menentukan arah kiblat, maka jika digabungkan akan menjadi rumus arah kiblat yang ada dalam literatur-literatur falak.

\footnotetext{
${ }^{18}$ Lihat foot note nomor 12
} 


\section{AL-MARSHAD: JURNAL ASTRONOMI ISLAM DAN ILMU-ILMU BERKAITAN \\ ISSN 2442-5729 (print) || ISSN 2598-2559 (online) \\ http://jurnal.umsu.ac.id/index.php/almarshad \\ DOI: 10.30596/jam.v\%vi\%i.5023|| Vol. 6, No. 2 Desember 2020}

b. Analisis matematik Rumus tan

Guna menganalisis secara matematis rumus tan ini pada perhitungan arah kiblat, maka kajian pada bagian ini dimulai dari persamaan (3) yang ada pada pembahasan sebelumnya.

Persamaan (3) tersebut bisa ditransformassikan ke dalam bentuk lain, sebagai berikut:

$\operatorname{cotan} B$

$=\frac{\sin a \operatorname{cotan} b}{\sin C}$

$-\cos a \operatorname{cotan} C$

Sebagaimana

diketahui dalam trigionometri bahwa $\operatorname{cotan} B=\frac{1}{\tan B}$

$$
\text { dancotan } C=\frac{\cos C}{\sin C}
$$

maka

persamaan (3) menjadi

$$
\begin{aligned}
& \frac{1}{\tan B} \\
& =\frac{\sin a \operatorname{cotan} b}{\sin C} \\
& -\cos a \frac{\cos C}{\sin C}
\end{aligned}
$$

$$
\frac{1}{\tan B}=\frac{\sin a \operatorname{cotan} b}{\sin C}-\frac{\cos a \cos C}{\sin C}
$$

$$
\begin{aligned}
& \frac{1}{\tan B} \\
& =\frac{\sin a \operatorname{cotan} b-\cos a \cos C}{\sin C} \\
& \text { Selanjutnya, kedua ruas }
\end{aligned}
$$

dibalik pembilang menjadi penyebut dan penyebut menjadi pembilang.

Sehingga diperoleh

$\frac{\tan B}{1}=\frac{\sin C}{\sin a \operatorname{cotan} b-\cos a \cos C}$

$\tan B$

$$
=\frac{\sin C}{\sin a \operatorname{cotan} b-\cos a \cos C} \ldots
$$

Persamaan (4) ini yang kemudian dikenal dengan rumus tan dalam perhitungan arah kiblat dalam buku ilmu ukur bola. Selaras dengan itu, persamaan (4) ini bisa ditransformasikan ${ }^{19}$ dalam persamaan lain dengan langkah sebagai berikut Mengingat,

$$
\begin{aligned}
& \mathrm{a}=90^{\circ}-\phi_{B} \\
& \mathrm{~b}=90^{\circ}-\phi_{A} \\
& \mathrm{C}=\lambda_{A}-\lambda_{B} \\
& \cos (90-\mathrm{x})=\sin (\mathrm{x}) \\
& \operatorname{Sin}(90-\mathrm{x})=\cos (\mathrm{x}) \\
& \cot (90-\mathrm{x})=\tan (\mathrm{x})
\end{aligned}
$$

Sehingga,

$$
\begin{gathered}
\operatorname{Sin} \mathrm{a}=\operatorname{Sin}\left(90^{\circ}-\phi_{B}\right) \\
=\operatorname{Cos} \phi_{B}
\end{gathered}
$$

$\operatorname{Cos} \mathrm{a}=\cos \left(90^{\circ}-\phi_{B}\right)$

$$
=\operatorname{Sin} \phi_{B}
$$

$$
\operatorname{cotan} \mathrm{b}=\operatorname{Cotan}\left(90^{\circ}-\phi_{A}\right)
$$

\footnotetext{
19 Agus Solikin. Matematika Falak. (Cirebon : Lovrinz
} Publishing, 2017). h. 62 - 63 


\section{AL-MARSHAD: JURNAL ASTRONOMI ISLAM DAN ILMU-ILMU BERKAITAN \\ ISSN 2442-5729 (print) || ISSN 2598-2559 (online) \\ http://jurnal.umsu.ac.id/index.php/almarshad \\ DOI: 10.30596/jam.v\%vi\%i.5023|| Vol. 6, No. 2 Desember 2020}

$$
=\operatorname{Tan} \phi_{A}
$$

Sehingga dengan demikian persamaan (4) menjadi,

$$
\tan B=\frac{\sin C}{\sin a \operatorname{cotan} b-\cos a \cos C}
$$

$\tan B$

$$
=\frac{\sin C}{\cos \phi_{B} \tan \phi_{A}-\sin \phi_{B} \cos C} \ldots
$$

Persamaan (5) ini merupakan rumus arah kiblat yang lain dengan menggunakan rumus cosinus dan rumus sinus. Namun yang perlu diketahui, rumus persamaan (5) ini jarang digunakan dalam literaturliteratur buku falak. sejauh kajian penelusuran penulis, lietarur falak yang menjelaskan penggunaan persamaan (5) ini dalam perhitungan arah kiblat yaitu mekanika benda langit ${ }^{20} \mathrm{dan}$ matematika falak ${ }^{21}$.

\section{Kesimpulan}

Berdasarkan kajian dari awal sampai akhir dapat disimpulkan bahwa rumus cos-sin dan rumus tan dalam perhitungan arah kiblat pada ilmu ukur bola, memiliki akar rumus yang sama

\footnotetext{
20 Rinto Anugraha. Mekanika benda langit.(Yogyakarta: Fisika FMIPA UGM. 2012). h. 36.

${ }^{21}$ Op. Cit. Lihat pula A. Solikin, “Aplikasi Aturan Cosinus dan Sinus Segitiga Bola dalam Perhitungan Arah Kiblat (Sebuah Relasi antara Matematika dan Agama)," MUST, vol. 1, no. 2, p. 164
}

dengan rumus perhitungan arah kiblat yang ada dalam literatur falak yaitu aturan cosinus dan sinus dalam segitiga bola. Rumus $\cos -$ sin perhitungan arah kiblat berdasarkan analisis yang telah dilakukan menjadi rumus arah kiblat yang dadalam lietartur-literatur falak.

\section{Daftar Pustaka}

Azhari. Susiknan. 2011. Ilmu falak peejumpn khazanah Islam dan sains modern. Yogyakarta: Suara Muhammadiyah.

Butar-Butar. Arwin Juli Rakhmadi. Khazanah Peradaban Islam Di Bidang Turats Manuskrip (Telaah Karakteristik, Konstruksi Dan Problempenelitian Naskah-Naskah Astronomi). .Medan: AlMarshad.Vol.1 no.1 tahun 2015.

Hambali. Slamet, 2011. Ilmu Falak.. Semarang: Program pascasarjana IAIN Walisongo.

Hosen dan Eka Nurhalisa. Akurasi Arah Kiblat Pemakaman Desa Ponteh Kecamatan Galis Kabupaten Pamekasan. Medan: AlMarshad.Vol.5 no.2 tahun 2019.

Kusdiono. 2002. Ilmu Ukur Segitiga Bola Bandung: Jurusan teknik geodesi Institut Teknologi

Lexy J. Moleong,, 2005. Metodologi Penelitian Kualitatif, Bandung: PT Remaja Rosdakarya.

Mukarram. Akh.. 2011. Ilmu Falak Dasar-Dasar Hisab Praktis. Sidoarjo: Grafika Media.

Nawawi. Abd. Salam. 2010. Ilmu Falak. Sidoarjo: Aqaba.

Purwanto. Agus. Penentuan arah Kiblat. makalah Pelatihan Hisab Falak, di PWM Jatim, tanggal 10 Juli 2011 
Slamet Hw. 2018/ Dasar -dasar Ilmu Ukur

Segitiga Bola..

Surakarta:Muhammadiyah University

Press.

Solikin. Agus. Matematika Falak. 2017. Cirebon : Lovrinz Publishing

Solikin A., "Aplikasi Aturan Cosinus dan Sinus Segitiga Bola dalam Perhitungan Arah Kiblat (Sebuah Relasi antara Matematika dan Agama)," MUST, vol. 1, no. 2, p. 164.

Suryana, 2010. Metodologi Penelitian. Bogor: Universitas Pendidikan Indonesia. 